\title{
History of Science and Science Education: New Conceptions, Old Instruments and Developing Institutions
}

\author{
Peter Heering1 ${ }^{1}$ Ian Winchester ${ }^{2}$
}

Published online: 9 April 2015

(C) Springer Science+Business Media Dordrecht 2015

This issue and the one that follows consist of a number of selected papers that were initially presented at the International Conference for the History of Science in Science Education (ICHSSE). This particular meeting, being the ninth in this series, took place in Flensburg (Germany) in 2012 and was devoted to discuss questions on enabling scientific understanding through historical instruments and experiments in formal and non-formal learning environments. The entire conference series originated from collaboration between Arthur Stinner (University of Manitoba) and Jürgen Teichmann (Deutsches Museum Munich). They established a series of meetings that aimed at familiarizing science teachers with topics from the history of science. This collection of papers in these two volumes are dedicated to the memory of Arthur Stinner, who unexpectedly died in 2014, and honour his large contribution to our common interests as science educators.

The Flensburg conference brought together science education researchers with historians of science in order to improve the interdisciplinary discourse of these groups. Consequently, the papers published in this issue can also be characterized by their interdisciplinary approach towards a history-based or historically informed science education. The different approaches towards the topic of the conference is also reflected by the papers in this special issue.

The first grouping of papers that form the present issue involves authors who are concerned to discuss original approaches to science education in which an historical component is often central. The second grouping which will be published in a following issue share a focus on the educational potential of historical instruments.

\footnotetext{
Ian Winchester

winchest@ucalgary.ca

1 University of Flensburg, Flensburg, Germany

2 University of Calgary, Calgary, Canada
} 
These could be kept in science museums or science centers - this would in some respect be the classical way to involve historical instruments into science education. Yet, we find also other approaches which either discuss a combination of classroom activities and field trips to museums, or bring instruments completely into the classroom. The collection of papers that share this interest will form the second volume of this collection. The contributions of Peter Heering, Don Metz, Juergen Teichmann, David Rhees, Gudrun Wolfschmidt and the paper jointly by Lidia Vernardizzi (Falomo) and Gabriela Albanezi will appear in that second volume.

The present volume will consist of the papers in the first grouping by Arthur Stinner, Elizabeth Cavicchi, Steven and Catherine Froese Klassen, Catherine Froese Klassen herself, Augustin Aduriz-Bravo, Elizabeth Cavicchi, Zoubeida Dagher and Susanne Heiniche.

The group of papers in this first issue can be described as being less addressing material and performative aspects of the sciences. Some of these papers are in this respect more conceptual discussions whilst others are more case studies. Several of the papers have in common that they discuss the use of narratives in science education from different perspectives:

Arthur Stinner's paper is a discussion of a puzzle in the history of cosmology, namely, the puzzle surrounding the topic of why the sky is dark at night, given that there are millions, perhaps billions of stars, that are visible. His approach is to present us with the history of the contributions that attempt to explain this phenomenon from the vantage point of six different cosmological accounts that have been popular since the seventeenth century. In a typical Stinner fashion he also provides the student with simple calculations that illustrate each of the potential solutions.

Stephen Klassen and Catherine Froese Klassen develop in their paper an argument which shows that the storytelling approach in science education can be legitimized by its potential to generate interest in the students. In doing so, they implicitly connect the approach with the history of science as the narratives they use in their analysis are based on the history of science. A comparable background can be found in the stories that are discussed by Catherine Froese Klassen in her contribution on analyzing stories in science education. Yet, in this contribution she takes a completely different approach when looking at the text in terms of analyzing their structure and content with respect to their categorization in terms of a literary genre. Her aim at creating a better categorization of the texts used in storytelling approaches is particularly valuable when it develops an empirical analysis and subsequently an understanding of which narratives are particularly beneficial (and in what sense) in science education.

Agustín Adurì-Bravo also discusses narratives, yet, in a broader sense as he is also using fictitious stories such as a novel by Roald Dahl. In doing so, he aims at enabling a teaching of (prospective and active) science teachers about the nature of science. Yet, he does not limit his discussion to some well-chosen examples, but presents also a detailed and rich philosophical basis of his approach. In doing so, he does not refer to the "classics" in the field but discusses modern conceptualizations such as the "new experimentalism" and the "semantic conception of scientific 
theories". Particularly remarkable appears his approach to structure the developments in the philosophy of science through several schematic representations.

Elizabeth Cavicchi shares in her contribution how learners become explorers. In her work, strongly influenced by the critical exploration approach that hearkens back to Eleanor Duckworth, she enables students to be explorers with respect to their developing an understanding, among others, of the works of Euclid and Archimedes.

She is able to show how input that originates from the history of science, science museums and science centers enable their students not only to construct a meaningful understanding of certain mathematical and scientific concepts, but at the same time to understand themselves as scientific explorers and thus to get insights into the nature of science itself.

Other papers have more the character of case study. For example Susanne Heinicke demonstrates the development of the uncertainty analysis with data from scientific measurements. In doing so, she is able to relate the historical development, which she sketches impressively with several historical case studies that serve as illustrations of this development. Moreover, she is also able to discuss these developments with respect to their relevance for science education, thus making a strong argument for a particular way of implementing this topic in a completely new, historically contextualized manner.

Zoubeida Dagher addresses relevant aspects of Mendel's "laws", in particular she discusses how the label "law" was attached to what Mendel described, whether this label is appropriate based on our understanding of what a scientific law is, and what this implies for biology education? In doing so, she does not limit herself to the actual case study under discussion but also addresses the far more general question of whether a law in biology is the same as a law in physics. On the basis of this discussion, she then asnalyses exemplary textbooks with respect to their treatment of Mendel's work and identifies shortcomings but also positive approaches. These examples are well chosen as they provide a strong idea of the potential spectrum of approaches towards Mendel and his work in educational contexts.

These papers, taken together, both the ones included in this volume and those planned for the next volume, show the potential of the history of science for science education. They also demonstrate the interdisciplinary character that is required in order to use the full potential of the history and philosophy of science in educational settings. In this respect it becomes evident that this approach does not have to be limited either to formal educational settings or to non-formal ones. What appears to be particularly fruitful is the collaboration between these areas. In particular, these collaborations appear to enable educators to access both the competencies of historians of science and historians can bring their knowledge, competencies and understanding to illuminate educational situations and settings. From this point of view, these papers can be seen as rather starting points rather than closure. We clearly need more examples in this respect. And we need, too, a deeper analysis of the effects that result from such collaborations. As a first step these papers clearly form a basis that can enrich future research as well as future education. 